\title{
Slowing Positive Streamer Propagation in Silicon and Ester Transformer Oil Using Multi-nanoparticles Technique
}

\author{
Ahmed Thabet ${ }^{1}$, Marwa Allam ${ }^{2}$, and Salma Shaaban ${ }^{3}$ \\ Nanotechnology Research Center, Electrical Engineering Dept., \\ Faculty of Energy Engineering, \\ Aswan University \\ Egypt. \\ ${ }^{1}$ athm@aswu.edu.eg, ${ }^{2}$ marwaallam89@hotmail.com, and ${ }^{3}$ salma@aswu.edu.eg
}

\begin{abstract}
This paper formulates new multi-nanoparticles technique for reducing positive streamer propagation in silicon and vegetables oils nanofluids; transformer oil nanofluids with multi-nanoparticles suspensions are blended to slow the propagation of positive streamer more than using individual nanoparticles, hence the insulation qualities are improved and breakdown voltage of nanofluid is expanded. This study indicated the influence of nanoparticle radius, nanoparticles' polarization, relative permittivity of oil, applied field and the charge density of nanoparticles interface. It is deduced that transformer oil-based nanofluids with conductive individuals and multi-nanoparticles suspensions have considerably higher impacts on slowing positive streamer than non-conductive nanoparticles. A comparative study has demonstrated the magnitude of deposited charge and charging time as result of using individual nanoparticles and multi-nanoparticles inside transformer oil.
\end{abstract}

Keywords-nanofluids, nanoparticles, ester oil, silicon oil, charges, positive streamers

\section{INTRODUCTION}

Nanotechnology is important industry, The governments worldwie funds researches of nanotechnology at over four billion dollars per year. The potential consequences of transformer failure can be quite damaging. It is therefore important to improve insulating properties of transformer oil [1-3]. Streamers are fundamental components in many types of gas discharges, such as the dielectric-barrier discharges between two electrodes [4-9]. Moreover, the production of thermal streamers may be caused by the terrestrial gamma ray flashes (TGFs) as discribed in[10, 11]. Streamers are propagating in such a way that their dynamics solely depend on the applied electric field; However, stable propagation of streamers occurs whenever an external field is equal to the critical field in case of constant radius and velocity. In addition, large magnitudes of fields lead to exponentially growing streamers, However, smaller ones lead to decaying streamers propagation [12]. From traditional perspective, nanoparticles improve the conductivity insulation and breakdown strength of the transformer oil. Conductive, dielectric and semi conductive nanoparticles also enhance dielectric strength of transformer oils as proved that electrons are attracted to polarized charges on nanoparticles. this action slows down the process of streamer propagation in transformer oil, This happen if the relaxation time constant of a nanoparticle is short relative to the timescales of streamer growth. Otherwise, this is affected only slightly [13-16]. The nanoparticles in transformer oil are induced or polarized under electric field in very short time scale; then, the positive and negative charges are generated at lower and upper hemispheres of nanoparticles. Charge induction of conductive nanoparticles is almost instantaneous. At dielectrics, the charges are formed due to the vertical electric field this process is called dielectric polarization. Dielectric polarization consists of displacement and turning-direction polarizations. Semi-conductors' polarization is mixture from induced charges and aside from electrons, positive holes are involved [17, 18]. It was indicated at [19] that the propagation of positive and negative streamers in nanofluids is deeply affected by the addition of $\mathrm{TiO}_{2}$ nanoparticles. Ester oils are free from petroleum, siloxanes and halogens, non-toxic, noncarcinogenic and completely biodegradable. Flash points of ester dielectric coolants and their are much higher than that of mineral oil. Transformer performance is enhanced by the use of ester products compared with mineral oils. It has been noticed that the transformer can be loaded by using Ester insulating at higher rating than it would be loaded with mineral oil and maintain its expected life. However, Silicone oil has small thermal ageing and dielectric loss. Also, Sillicon oils have low rate of heat release, minimal damage from fire, as it has self extinguishing behaviour, thus, Silicone oils offer best thermal stability [20-25]. Streamer propagation characteristic differ from breakdown voltage in pure oil and nanofluids with respect to the change of space charge distribution of shallow trap in nanofluid. Adding aluminum nanoparticles enhance the mean lightening impulse breakdown voltages of nanofluids [26, 27]. This paper investigated the effects, types and concentrations of nanoparticles on positive streamer propagation in silicon and ester transformer oil. Then, the characterization of transformer oil nanofluids under individual and multinanoparticles techniques is discussed. Therefore, a comparative study is done for specifying the best technique (individual, multi-nanoparticles) for controlling the positive streamer propagation in silicon and ester transformer oils.

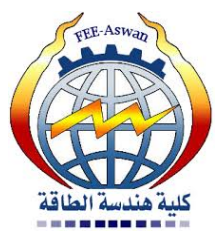




\section{THEORETICAL MODEL ANALYSIS}

\section{A. Charging Dynamics for Individual Nanoparticles}

Modeling the charging of the nanoparticles in oil is necessary to explain the electrodynamics within transformer oil-based nanofluids. Under field induction, the charge of conductive nanoparticles is instantaneous (Eq. 1).

However, the charges of dielectric like $\left(\mathrm{Al}_{2} \mathrm{O}_{3}\right)$ or semiconductor like ( $\mathrm{ZnO})$ nanoparticles are calculated by (Eq. 2). Dielectric polarization occurs by displacement and turningdirection polarizations. Positive charge density of nanoparticle on different types of nanoparticles, $s_{s}$ in $\mathrm{C} / \mathrm{m}^{3}$ [18].

$$
\begin{aligned}
& s_{s}=3 \varepsilon_{1} E_{0} \cos \theta \\
& s_{s}=3 \varepsilon_{1} E_{0} \cos \theta \frac{\varepsilon_{2}-\varepsilon_{1}}{2 \varepsilon_{1}+\varepsilon_{2}}
\end{aligned}
$$

where, $\mathrm{E}_{0}$ is applied field in V/m. $\theta$ is angle in degrees that is occupied by negative charges on nanoparticle's positive hemisphere, $\varepsilon_{1}$ and $\varepsilon_{2}$ are permittivities of transformer dielectric liquid and nanoparticle respectively,

Once nanoparticles are saturated with negative charges, the magnitude of saturation charge on conductive nanoparticles (Eq. 3) in Columns(C). However, saturation charge for dielectric and semi-conductive nanoparticles (Eq. 4) in (C) is calculated as follows:

$$
\begin{aligned}
& Q_{s}=-12 \varepsilon_{1} E_{0} R^{2} \\
& Q_{s}=-12 \varepsilon_{1} E_{0} R^{2} \cdot \frac{\varepsilon_{2}-\varepsilon_{1}}{2 \varepsilon_{1}+\varepsilon_{2}}
\end{aligned}
$$

Where, $\mathrm{R}$ is radius of nanoparticle in $(\mathrm{m})$.

As the saturation charges on nanoparticles are proportionate to $R^{2}$. Deposited charge on a nanoparticle $Q(t)$ in $(\mathrm{C})$ can be expressed by [Eq. 5].

$$
Q(t)=\frac{Q_{s} \frac{t}{\tau_{p c}}}{1+\frac{t}{\tau_{p c}}}, \tau_{p c}=-\frac{4 \varepsilon_{1}}{\rho_{e} \mu_{e}}
$$

Where,

$\mu_{e}$ is mobility of electron, $\rho_{e}$ is uniform charge density of electron, $\tau_{p c}$ is the time constant for nanoparticle charging in (Sec).

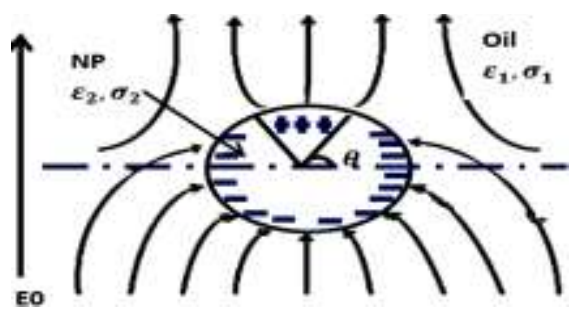

Fig. 1 Electric field lines on individual nanoparticle in transformer oil

\section{B. Charging Dynamics for Multi-nanoparticles}

The electric field lines after a uniform z-directed of electric field are applied to multi-nanoparticles in nanofluid [28]. Firstly, multinanoparticles in transformer oils would be induced or polarized under electric field in a very short time-scale as shown in Fig. 2 (a), however, Fig. 2 (b) shows negative and positive charges are concerted at the upper and lower hemispheres of nanoparticle. The free electrons that produced from ionization of transformer oil are immediately quickly attracted to positively charged hemisphere of nanoparticle as shown in Fig. 2 (c). Finally, Fig. 2 (d) shows the nanoparticle that is saturated with negative charges and electrons are no more scavenged. Those process slow down free electrons in nanofluids by converting them into slow negative particles so propagation of streamers in nanofluids will be slower than their propagation in pure oils.

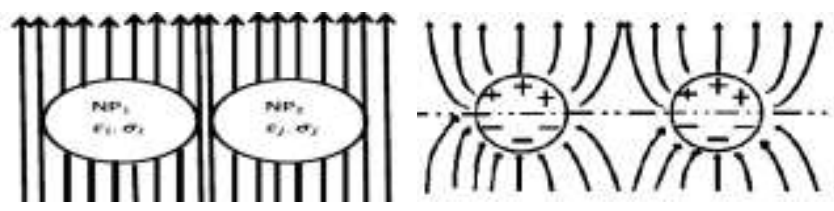

(a)

(b)

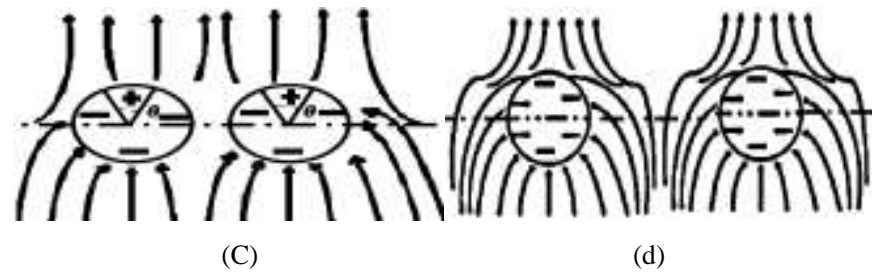

Fig. 2 Electric field lines on multi-nanoparticles in transformer oil.

\section{C. $\quad$ Surface Charge Density of Multi-nanoparticles $\left(S_{t}\right)$.}

Charge density on the surface of nanoparticle results from induced or polarized positive charge which appears when the nanoparticle is exposed to electrical filed. The density of surface charge mainly determines the effectiveness of nanoparticle in attracting electrons. The density of surface charge of multi conductive nanoparticles is expressed in (Eq. 6) however; (Eq. 7) gives the density surface charge of dielectric or semi-conducive nanoparticle. (Eq. 8) gives the value of density surface charge whenever conductive and dielectric nanoparticles are used as follows [28]:

$$
\begin{aligned}
& \mathrm{s}_{\mathrm{t}}=3 \mathrm{n} \varepsilon_{1} \mathrm{E}_{0} \cos \theta \\
& \mathrm{s}_{\mathrm{t}}=3 \varepsilon_{1} \mathrm{E}_{0} \cos \theta \sum_{\mathrm{i}=1}^{\mathrm{n}} \frac{\varepsilon_{\mathrm{i}+1}-\varepsilon_{1}}{2 \varepsilon_{1}+\varepsilon_{\mathrm{i}+1}} \\
& \mathrm{~s}_{\mathrm{t}}=3 \varepsilon_{1} \mathrm{E}_{0} \cos \theta\left(\sum_{\mathrm{i}=1}^{\mathrm{n}}\left(\frac{\varepsilon_{\mathrm{i}+1}-\varepsilon_{1}}{2 \varepsilon_{1}+\varepsilon_{\mathrm{i}+1}}\right)+\mathrm{m}\right)
\end{aligned}
$$

where, $\varepsilon_{1}$ is relative permittivity of oil , $n$ is the total number of used nanoparticles, $m$ is the total number of conductive nanoparticles, $\theta$ is the angle of negative charges on positive hemi sphere, $\varepsilon_{i+1}$ is relative permittivity of dielectric or semi-conducive nanoparticle

\section{Saturation Charge of Multi-nanoparticles $\left(Q_{s t}\right)$ in $(C)$.}

Saturation charge of multi-nanoparticles is maximum electrons' charge that nanoparticle could stand on its surface. It depends on relative permittivity of oil, type of nanoparticles; (magnetic or non-magnetic) and relative permittivity of non-magnetic nanoparticles [28]. Thus, the value of saturation charge collected on surface of conductive multi-nanoparticles can be calculated from Eq. (9), however, Eq. (10) gets saturation charge of dielectric or semi-conducive nanoparticle; then, Eq. (11) gives saturation charge of conductive and dielectric nanoparticles.

$$
\begin{aligned}
& \mathrm{Q}_{\mathrm{st}}=-12 \varepsilon_{1} \mathrm{E}_{0}\left(\sum_{\mathrm{j}=1}^{\mathrm{n}} \mathrm{R}_{\mathrm{j}}{ }^{2}\right) \\
& \mathrm{Q}_{\mathrm{st}}=-12 \varepsilon_{1} \mathrm{E}_{0}\left(\sum_{\mathrm{i}=1}^{\mathrm{n}} \mathrm{R}_{\mathrm{i}+1}{ }^{2} \cdot \frac{\varepsilon_{\mathrm{i}+1}-\varepsilon_{1}}{2 \varepsilon_{1}+\varepsilon_{\mathrm{i}+1}}\right)
\end{aligned}
$$


$\mathrm{Q}_{\mathrm{st}}=-12 \varepsilon_{1} \mathrm{E}_{0}\left(\sum_{\mathrm{i}=\mathrm{i}}^{\mathrm{n}} \mathrm{R}_{\mathrm{i}+1}{ }^{2} \cdot \frac{\varepsilon_{\mathrm{i}+1}-\varepsilon_{1}}{2 \varepsilon_{1}+\varepsilon_{\mathrm{i}+1}}+\sum_{\mathrm{j}=1}^{\mathrm{m}} \mathrm{R}_{\mathrm{j}}^{2}\right)$

where, $R_{j}$ is the radius of conductive nanoparticle, $\mathrm{n}$ is the number of used nanoparticles, $\mathrm{m}$ is the total number of conductive nanoparticles, $R_{i+1}$ is the radius of dielectric or semi-conducive nanoparticle.

\section{E. Deposited Charge of Multi-nanoparticles $\left(Q_{t t}\right)$.}

It represents the rate of electrons' charge deposited on nanoparticles in (C). The time measures with streamer propagation not exceed few nanoseconds. Thus, the multinanoparticles need short time to be charged compared to the time of streamer propagations as follows [28]:

$$
Q_{t t}=\frac{t / \tau_{p c}}{1+t / \tau_{p c}} \cdot Q_{s t}
$$

Usage of STO-50 Silicone transformer oil comes back to its high dielectric strength, wide service temperature range, high flash point, and low vapor pressure, low viscosity change at extremely high and low temperatures and inertness to virtually all substrates [29, 30]. On the other side, Ester oils (MIDEL7131) are selected as it is highly biodegradable insulating oil for use in environmentally sensitive applications. It has excellent electrical characteristics and thermal stability. Ester oils (MIDEL7131) give complete solution for biodegradable applications than conventional transformer oils because of low vapor pressure, low volatilities, high flash point, Lubricity and high polarity of ester molecules causes a high solvency inside the fluid [30, 32]. Electrical properties of selected nanoparticles [33, 34] are specified in table I.

TABLE I. Electrical Properties of Selected Insulting Oils and Nanoparticles

\begin{tabular}{|c|c|c|}
\hline Materials & Relative Permittivity & Conductivity (S/m) \\
\hline MIDEL7131 oil & 3.2 & $10^{-11}$ \\
\hline Silicon oil & 2.7 & $10^{-12}$ \\
\hline $\mathrm{ZnO}$ & 7.4 & $10^{-6}$ \\
\hline $\mathrm{MgO}$ & 9.7 & $5.011^{*} 10^{-7}$ \\
\hline $\mathrm{TiO}_{2}$ & 90 & $10^{-11}$ \\
\hline $\mathrm{SiO}_{2}$ & 4.5 & $10^{-11}$ \\
\hline $\mathrm{Graphite}_{\mathrm{LiTiO}}$ & 15 & $5.011^{*} 10^{-4}$ \\
\hline $\mathrm{Fe}_{3} \mathrm{O}_{4}$ & 40 & $2.51^{*} 10^{-9}$ \\
\hline \multicolumn{2}{|}{} & $1^{*} 10^{4}$ \\
\hline
\end{tabular}

\section{RESULTS AND ANALYSIS}

A small result in of nanoparticles inside the transformer oil can slow the streamer propagation and rising breakdown voltage. The benefit of multi-nanoparticle technique is using multi-advantages of different nanoparticles in the same transformer nanofluids; like, one type of nanoparticles has high relative permittivity for slowing streamer propagation and the other type has small relative permittivity for keeping the effective relative permittivity of nanofluid at reasonable value [18]. The following results have been calculated for slowing positive streamer propagation at electric field equals $10^{8} \mathrm{~V} / \mathrm{m}$ and nanoparticles radii equals $25 \mathrm{~nm}$.

\section{A. Effect of Filed on Nanoparticle's Density Charge}

Expanding filed that applied on means high rate of both displacement polarizations and dipole polarization, giving more spellbound charges, which thusly upgrade the thickness of charge on nanoparticle. Fig. 3 and 4 demonstrate charge density of nanoparticle accusing increment field MIDEL7131and silicon oils respectively. In case of individual nanoparticles, $\mathrm{Fe}_{3} \mathrm{O}_{4}$ nanoparticle dosn't have the most astounding permittivity but it gives prevalent response with expanding the applied field as its polarization rely on upon having an ocean of free electrons not in its permittivity. In case of using multi-nanoparticles $\left(\mathrm{Fe}_{3} \mathrm{O}_{4}+\mathrm{MgO}\right)$ give highest response with increasing applied field as it's supported by induced polarization of the same concentration of $\mathrm{Fe}_{3} \mathrm{O}_{4}$ nanoparticles. Multi-nanoparticles $\left(\mathrm{ZnO}+\mathrm{TiO}_{2}\right)$ record second rate of increments, however $\left(\mathrm{SiO}_{2}+\mathrm{LiTaO}_{3}\right)$ come at the last rank.

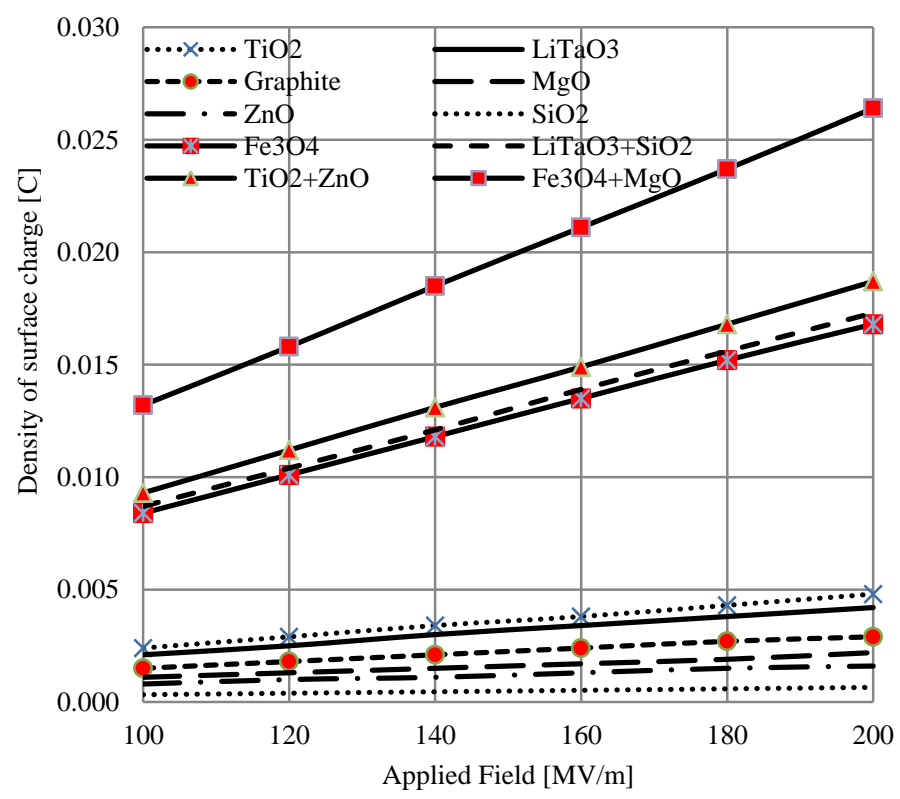

Fig. 3 Variation of surface charge density with applied field in MIDEL7131nanofluids

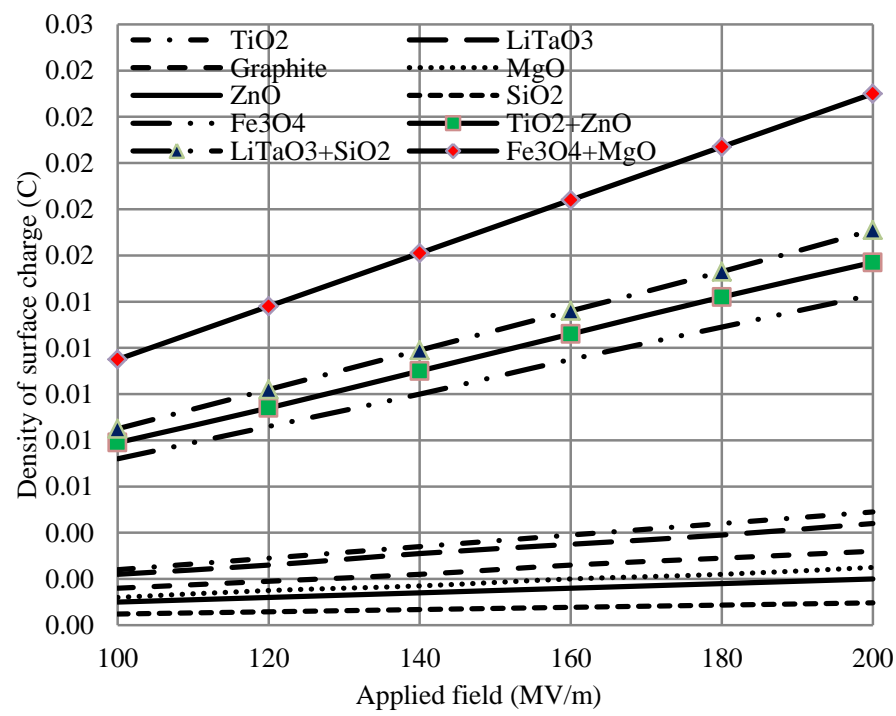

Fig. 4 Variation of surface charge with applied field in silicon nanofluids 


\section{B. Effect of Theta on Charge Density of Dielectric Liquids}

Fig. 5 and 6 demonstrate the charge density of individual and multi-nanoparticle interface accusing reductions of $\theta$ from $\pi / 2$ to 0 in MIDEL7131and silicon oils. As theta $(\theta)$ represents negative charges on positive hemi-circle of nanoparticle, so in the event that it is 0 , that implies all positive surface of nanoparticle doesn't have any negative charges. Individual nanoparticles $\left(\mathrm{Fe}_{3} \mathrm{O}_{4}\right)$ give the most response depending on its induced charges. The distinctions in qualities between Silicon oil and Ester oil back to contrasts in their permittivities. In case of multi-nanoparticle, the density of surface charge increases with decreasing of Theta, thus, multi-nanoparticles $\left(\mathrm{Fe}_{3} \mathrm{O}_{4}+\mathrm{MgO}\right)$ give highest magnitude of charges on their surface supported by induced polarization of $\mathrm{Fe}_{3} \mathrm{O}_{4}$ nanoparticles. Upon using non-magnetic multi-nanoparticles increase of charge density would arrange according to their permittivities $\left(\mathrm{ZnO}+\mathrm{TiO}_{2}\right)$ nanoparticles then, $\left(\mathrm{LiTaO}_{3}+\mathrm{SiO}_{2}\right)$.

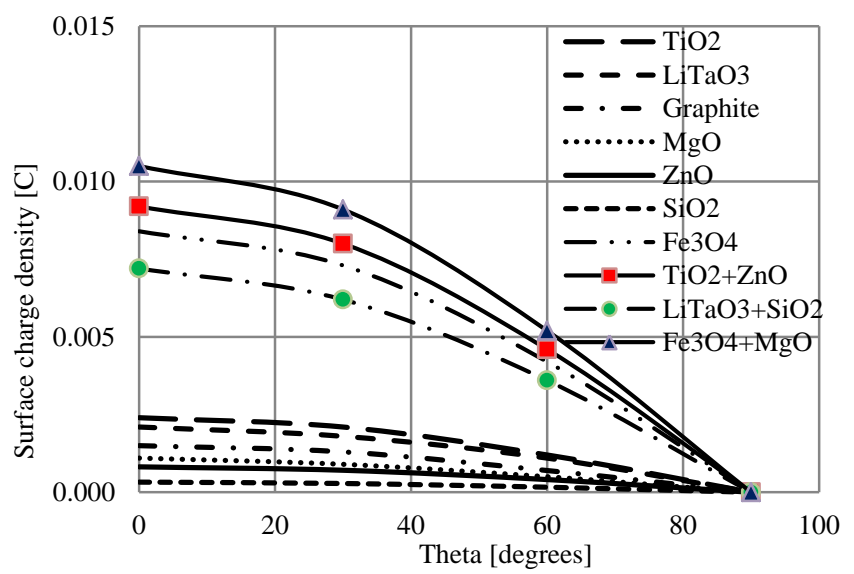

Fig. 5 Variations of surface charge with Theta in MIDEL7131nanofluids

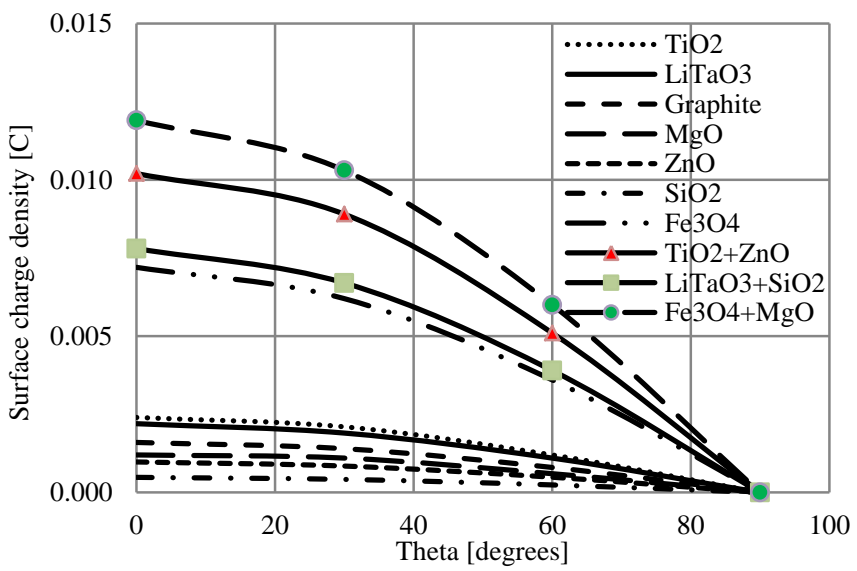

Fig. 6 Variations of surface charge with Theta in silicon nanofluids

\section{Effect of Radius on Saturation Charge of nanoparticle}

It is noticed that adding individual nanoparticles gives saturation charge values differ from the values that is given by multi-nanoparticles with the same radii. Fig. 7 and 8 show variations of charge density on surface of individual and multi-nanoparticles with radius in silicon and MIDEL7131 oil. More electrons can be stored on nanoparticle in case of higher nanoparticle radius. A huge augmentation has showed up in number of electrons with expanding the range of nanoparticle that demonstrated the significance of span as fundamental consideration obstructing of positive streamer because of the expanding capacity of nanoparticle to than expanding connected permittivity.

\section{Effect of Time on Deposited Charge Magnitude}

Fig. 9 and Fig. 10 demonstrate the charging procedures of various types of individual and multi-nanoparticles in silicon and MIDEL7131 oils. Nanoparticles are trapping electrons rapidly particularly in the first nanoseconds then trapping process moderates until the nanoparticle immersed with negative charges and afterward repulses electrons. The charging procedures of the selected nanoparticles are sufficiently snappy to catch the electrons in nanoparticle streamers.

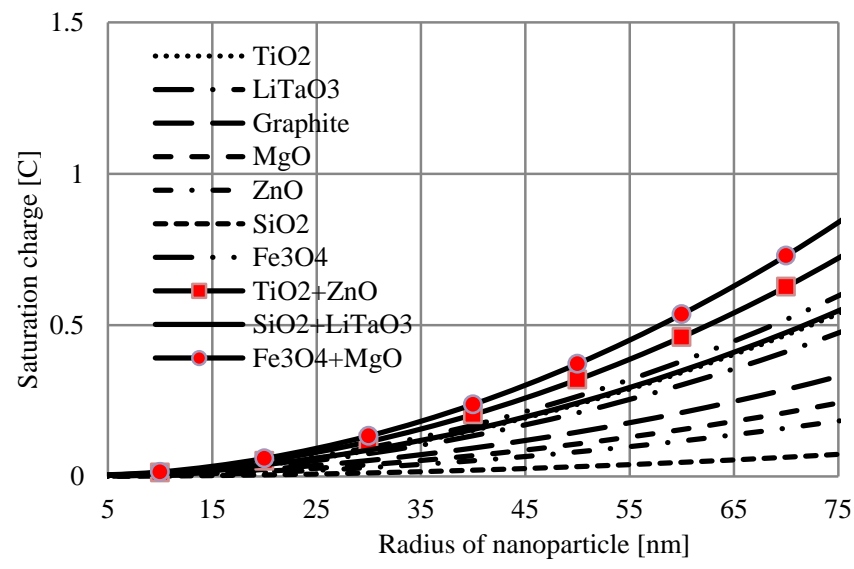

Fig. 7 Variations of saturation charge of individual nanoparticle with radius in MIDEL7131 nanofluids

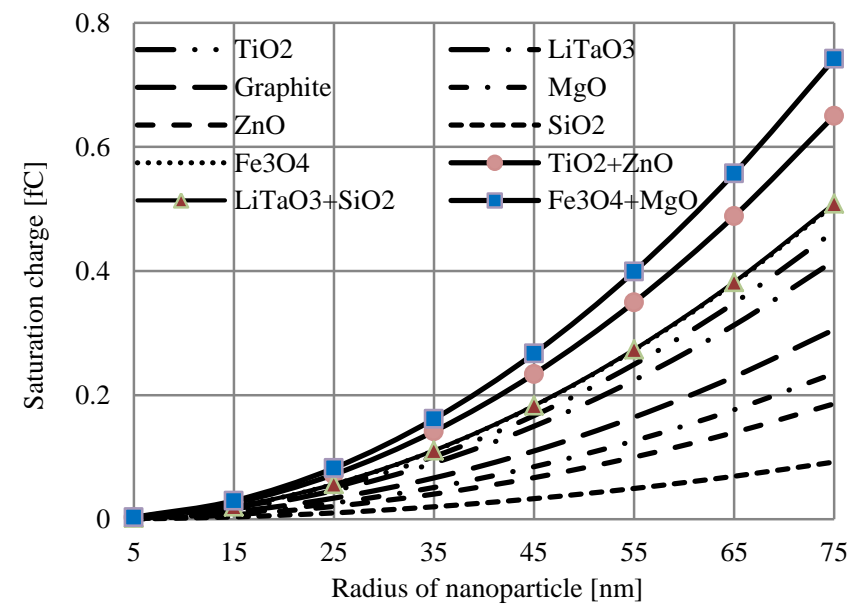

Fig. 8 Variations of saturation charge of nanoparticle with radius in silicon oil

\section{E. Effect of Radius on Deposited Charge Nanoparticle}

Nanoparticle radius has effective influence in increasing magnitude of deposited charge but this influence differs upon using individual nanoparticles or multi-nanoparticles. Fig 11 and 12 show the magnitude of deposited charge increases rapidly within increasing radius of nanoparticles. 


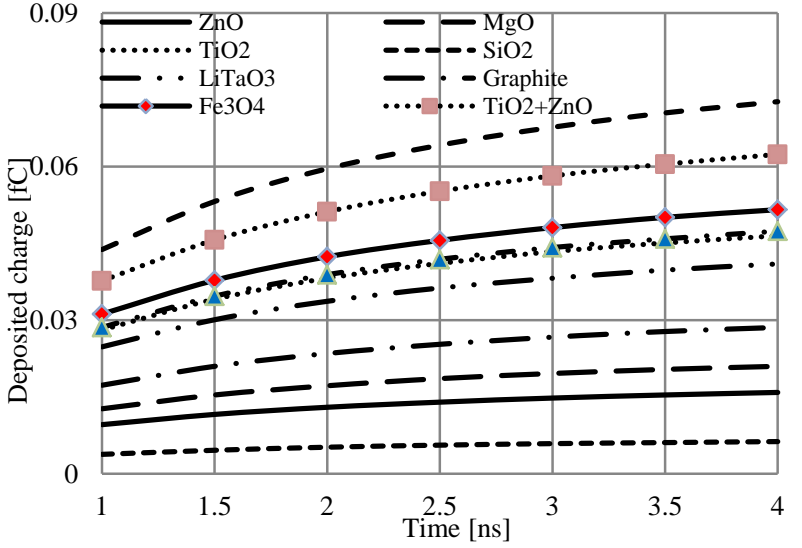

9 Variations of deposited charge with time interest for streamer growth in MIDEL7131 nanofluids

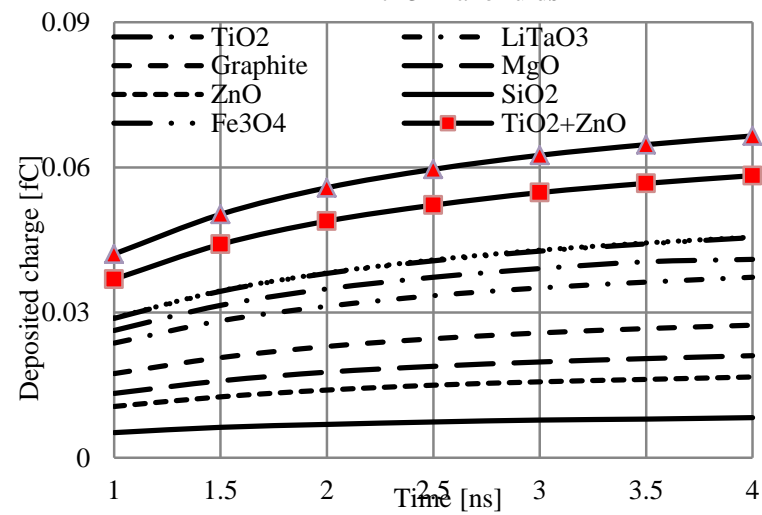

10 Variations of deposited charge with growth time in Silicon oil

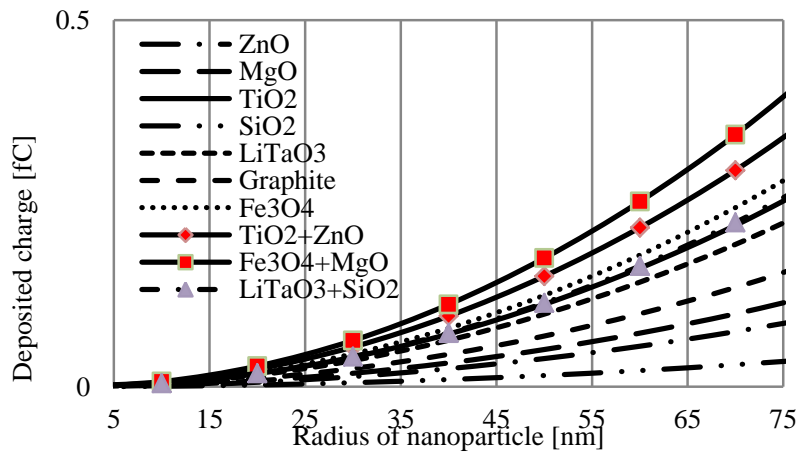

Fig. 11 Variations of deposited charge with radius in MIDEL7131nanofluids

In case of individual nanoparticles, $\mathrm{Fe}_{3} \mathrm{O}_{4}$ nanoparticles have the highest increment of deposited charge that depends on induced charges and in turn depends on local conductivity of nanoparticle. However, multi-nanoparticles $\left(\mathrm{Fe}_{3} \mathrm{O}_{4}+\mathrm{MgO}\right)$ which don't have highest elevated permittivity, yet they give the most astounding addition with radius supported by nanoparticles of $\mathrm{Fe}_{3} \mathrm{O}_{4}$. It may be noticed that $\left(\mathrm{ZnO}+\mathrm{TiO}_{2}\right)$ nanoparticles which have the most astounding relative permittivity come after $\left(\mathrm{Fe}_{3} \mathrm{O}_{4}+\mathrm{MgO}\right)$ in measure of augmentation with span.

\section{COMPARATIVE STUDY FOR USING INDIVIDUAL AND MULTI-NANOPARTICLES}

Table. II providing a comparison between the magnitude of deposited charge and attachment time constant of individual and multi-nanoparticles in silicon and MIDEL7131 fluids where, field $=10^{8} \mathrm{~V} / \mathrm{m}, \mathrm{R}=25 \mathrm{~nm}$ at the first nanosecond of streamer time. Related to individual and multi-nanoparticles increases the magnitude of deposited charge depending on their polarizability and transformer oil permittivities. Transformer oil based- $\mathrm{Fe}_{3} \mathrm{O}_{4}$ can absorb larger value of free electrons than other unique nanofluids and $\left(\mathrm{LiTaO}_{3}+\mathrm{SiO}_{2}\right)$ nanofluids. On the other hand, multi-nanoparticles $\left(\mathrm{Fe}_{3} \mathrm{O}_{4}+\right.$ $\mathrm{MgO}$ ) becomes at first rank. The attachment time is the time needed for nanoparticle to catch $80 \%$ of nanoparticle's charge. It's so important for effective nanoparticle to have very small attachment time. $\mathrm{Fe}_{3} \mathrm{O}_{4}$ nanoparticles will consume the smallest time in catching the major of their charge among selected individual nanoparticles in MIDEL7131 and Silicon oils. In case of using multi-nanoparticles, $\left(\mathrm{Fe}_{3} \mathrm{O}_{4}+\mathrm{MgO}\right)$ nanoparticles have the best time among them.

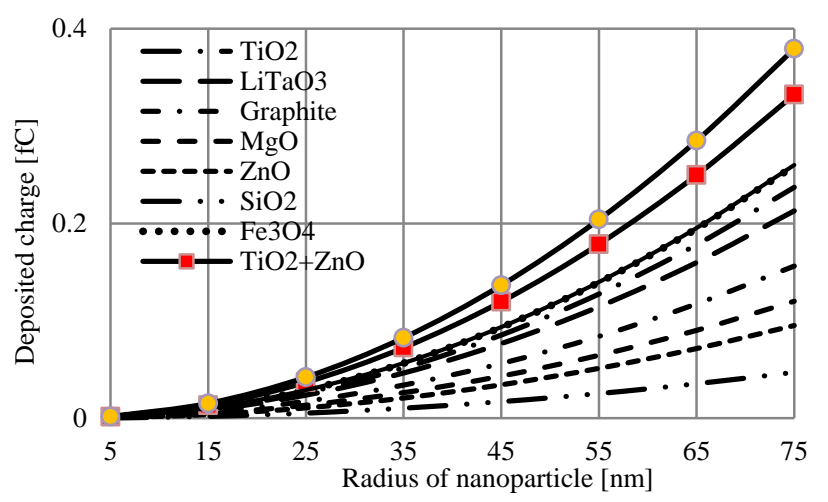

Fig. 12 variations of deposited charge with radius in Silicon oil nanofluids

TABLE. II. Magnitudes of deposited charge and attachment time constant for individual and multi-nanoparticles

\begin{tabular}{|c|c|c|c|c|}
\hline \multirow{2}{*}{ Nanoparticles } & \multicolumn{2}{|c|}{$\begin{array}{c}\text { Magnitude of deposited } \\
\text { charge }(\mathbf{C}) * 10^{-17}\end{array}$} & \multicolumn{2}{c|}{$\begin{array}{c}\text { The Attachment time } \\
\text { constants }\left(\boldsymbol{\tau}_{\boldsymbol{n}}\right) \text { in (ns) }\end{array}$} \\
\cline { 2 - 5 } & $\begin{array}{c}\text { MIDEL } \\
\text { 7131 }\end{array}$ & Silicon oil & $\begin{array}{c}\text { MIDEL } \\
\text { 7131 }\end{array}$ & Silicon oil \\
\hline $\mathrm{Fe}_{3} \mathrm{O}_{4}$ & 3.1155 & 2.881 & 1.8 & 1.73 \\
\hline $\mathrm{TiO}_{2}$ & 2.8079 & 2.63 & 1.825 & 1.75 \\
\hline $\mathrm{LiTaO}_{3}$ & 2.4761 & 2.372 & 1.84 & 1.77 \\
\hline $\mathrm{MgO}$ & 1.2683 & 1.333 & 1.89 & 1.82 \\
\hline $\mathrm{ZnO}$ & 0.95913 & 1.064 & 1.84 & 1.78 \\
\hline $\mathrm{SiO}$ & 0.38225 & 0.5201 & 1.82 & 1.715 \\
\hline $\mathrm{Fe}_{3} \mathrm{O}_{4}+\mathrm{MgO}$ & 4.384 & 4.214 & 1.85 & 1.75 \\
\hline $\mathrm{LiTaO}_{3}+\mathrm{SiO}$ & 2.858 & 2.892 & 1.86 & 1.77 \\
\hline $\mathrm{TiO}_{2}+\mathrm{ZnO}$ & 3.7661 & 3.694 & 1.89 & 1.78 \\
\hline
\end{tabular}

\section{CONCLUSIONS}

- Magnetic nanoparticles give trapping electrons higher than non-magnetic nanoparticles due to its induced charges in silicon or MIDEL7131. Moreover, multi- nanoparticles have the ability of slowing streamer and absorbing large number of electrons at very limited time compared to individual nanoparticles.

- Increasing radius is more effective for increasing the magnitude of deposited charge on the nanoparticles than electric applied field or relative permittivity.

- Selection of silicon oil is better than MIDEL7131 oil based on inherent time that needed for the streamer propagation in both nanotechnology techniques. 


\section{ACKNOWLEDGEMENTS}

The present work was supported by Nanotechnology Research Center at Aswan University that is established by aiding the Science and Technology Development Fund (STDF), Egypt, Grant No: Project ID 505, 2009-2011.

\section{REFERENCES}

[1] Y. Du, Y. Lv, C. Li, M. Chen, Y. Zhong, J. Zhou, X. Li, Y. Zhou., "Effect of semi conductive nanoparticles on insulating performances of transformer oil", IEEE transactions on Dielectrics and Electrical Insulation., Vol. 19.No. 3, pp.770 - 776, 2012.

[2] M. C. Roco, W. S Bainbridge, "Societal implications of nanoscience and nanotechnology: maximizing human benefit", Journal of Nanoparticle Research., Vol. 7, No.1, pp. 1-13, 2005.

[3] D. Peterchuck, A. Pahwa, "Sensitivity of transformer's hottest-spot and equivalent aging to selected parameters", IEEE Transactions on Power Delivery., Vol. 17, pp.996-1001, 2002.

[4] Q. Jianqi, P. P. Victor, "On the propagation of streamers in electrical discharges", Journal of applied physics, Vol. 47, pp.1-9, 2014.

[5] F. M. O'Sullivan, "A Model for the Initiation and Propagation of Electrical Streamers in Transformer Oil and Transformer Oil Based Nanofluids", PhD Thesis. Dissertation. Massachusetts Institute of Technology, Cambridge, MA, USA, 2007.

[6] V. Segal, A. Hjortsberg, A. Rabinovich, D. Nattrass and K. Raj, "AC $(60 \mathrm{~Hz})$ and impulse breakdown strength of a colloidal fluid based on transformer oil and magnetite nanoparticles". IEEE International Symposium on Electrical Insulation (Cat. No.98CH36239), USA. pp.619-622, 1998.

[7] V. Segal, A. Rabinovich, D. Nattrass, K. Raj, A. Nunes, "Experimental study of magnetic colloidal fluids behavior in power transformers", J. Magnetism and Magnetic Materials., Vol. 215, pp. 513-515, 2000.

[8] J. G. Hwang, F. M. O'Sullivan, M. Zahn. O. Hjortstam, L. A. A Pettersson, R. Liu , "Modeling of streamer propagation in transformer oil-based nanofluid", IEEE, Annual Report Conference on Electrical Insulation and Dielectric Phenomena (CEIDP).pp. 61-366, 2008.

[9] J. G. Hwang, M. Zahn, F. M. O’Sulliva, L. A. Pettersson, O. Hjortstam, R. Liu, "Effects of nanoparticle charging on streame development in transformer oil-based nanofluids", Journal of applied physics., Vol. 107, No.1, 2010.

[10] P. Kopcansky, L. Tomco, K. Marton, M. Koneracka, I. Potocova and M. Timko, "The de dielectric breakdown strength of magnetic fluids based on transformer oil", Journal of Magnetism and Magnetic Materials., 289, pp.415-418, 2005.

[11] M. Chiesa, S. K. Das, "Experimental investigation of the dielectric and cooling performance of colloidal suspensions in insulating media", Colloids and Surfaces A: Physicochemical and Engineering Aspects, Vol.335, No1, pp88-97, 2009

[12] I. Gallimbert, "A computer model for streamer propagation", Journal of Physics D: Applied Physics.; Vol.5, No.12, 1972.

[13] T. Takada, Y. Hayase, Y. Takada, T. Okamoto, "Space charge trapping in electrical potential well caused by permanent and induced dipoles for LDPE/MgO Nanocomposite", IEEE Transactions on Dielectrics and Electrical Insulation., Vol.15, No. 1, pp.152-160, 2008.

[14] Y. Du, Y. Lv, C. Li, M. Chen, J. Zhou, X. Li, Y.Zhou, Y. Tu. Effect of electron shallow trap on breakdown performance of transformer oil-based NFs. Journal of Applied Physics. Vol.110, No.10, pp.1-4, 2011.

[15] Y. Du, Y. Lv, C. Li, M. Chen, Y. Zhong, J. Zhou, X. Li, Y. Zhou.,” Insulating Property and Mechanism of Semiconducting Nanoparticles Modified Transformer Oils. Proc. Chinese Soc.Electr. Eng. (CSEE), Vol. 32, No.10, pp.177-182, 2012.
[16] Y. X. Zhou, Y. S. Wang, J. H. Tian, Y. C. Sha, X. X. Jiang, S. Y. Gao, Q. Nie," Breakdown Characteristics in Transformer Oil Modified by Nanoparticles", Gaodianya Jishu/ High Voltage Engineering., Vol. 36, No. 5, pp. 1155-1159, 2010.

[17] W. Sima, J. Shi, Q. Yang, S. Huang, X. Cao, "Effects of Conductivity and Permittivity of Nanoparticle on Transformer Oil Insulation Performance Experiment and Theory", IEEE Transactions on Dielectrics and Electrical Insulation., Vol. 22, No. 1, pp. $380-$ 390, 2015.

[18] A. Thabet, S. A. Shaaban, M.Allam," Enhancing Dielectric Constant of Transformer Oils Using Multi-Nanoparticles Technique under Thermal Conditions", IEEE, International Middle East Power System Conference (MEPCON). Helwan, Egypt, pp. 220 - 225, 2016.

[19] Y. Lv, Y. Ge, Ch. Li, Q. Wang, Y. Zhou, B. Qi, K. Yi, X. Chen, J. Yuan ,"Effect of TiO2 Nanoparticles on Streamer Propagation in Transformer Oil under Lightning Impulse Voltage", IEEE Transactions on Dielectrics and Electrical Insulation., Vol. 23, No.4, PP. $2110-2115,2016$

[20] N. Zimmerman, R. Bass, "Consideration of Ester-Based Oils as Replacements for Transformer Mineral Oil. Portland State UniversityMaseeh College of Engineering \& Computer Science Dept. of Electrical \& Computer Engineering”, Report number: 160, 2014.

[21] K. Bandara, C. Ekanayake, T. Saha, H. Ma," Performance of Natural Ester as a Transformer Oil inMoisture-Rich Environments", Energies Journal., Vol.9, No.258, pp.1-13, 2016.

[22] M. Rycroft," Vegetable oil as insulating fluid for transformers", Energize Journal., pp.37-40, 2014.

[23] I. L. Hosier, A. S. Vaughan, S. G. Swingler, G. Moss, "Thermal and electrical ageing of silicone oil", 16th International Symposium on High Voltage Engineering., UK, PP.1-5.

[24] Siemens Report "Transforming future trends into innovations: Siemens Alternative Insulating Liquid Transformers Energy, Sector Power, and Transmission Division Transformers" Germany. Dispo 19200, c4bs No. 7480. 2014.

[25] F. Ronny, P. Georg, Siemens AG, "The Green Machine: Renewable materials for transformer. Electricity Today”, India, 2014.

[26] M. Rafiq, Ch. Li, D. Khan, H. Zhifeng, Y. Lv, K. Yi ,” Preparation and Breakdown Properties of Mineral Oil Based Alumina Nanofluids.North China Electric Power University. International Conference on Emerging Technologies (ICET), pp. 1-3, 2015.

[27] P. Wedin," Electrical breakdown in dielectric liquids-a short overview", IEEE Electrical Insulation Magazine., Vol. 30, pp. 20-25, 2014.

[28] A.Thabet, M. Allam and S.A Shaaban, "Investigation on enhancing breakdown voltages of transformer oil nanofluids using multinanoparticles technique" IET Generation Transmission and Distribution Journal, DOI: 10.1049/iet-gtd.2017.1183.

[29] J. G. Hwang, M. Zahn, F. M. O'Sullivan, L. A. A. Pettersson, O. Hjortstam and R. Liu, "Effects of nanoparticle charging on streamer development in transformer oil-based nanofluids", Journal of applied physics., Vol. 114, 2013.

[30] Y. Endah, "Analysis of dielectric properties Comparison between mineral oil and Synthetic ester oil", Thesis, Faculty of Electrical Engineering, Mathematics, and Computer Science Delft University of Technology. 2010.

[31] Clearco Products Co, Inc. STO-50 "Silicone Transformer Oil" CAS No: 63148-62- 9, 2015

[32] S J. Randles "Esters in Synthetics, Mineral Oils, and Bio-Based Lubricants: Chemistry and Technology", L. R. Rudnick, Ed. Florida: CRC Press, Taylor \& Francis Group, 2006.

[33] Lew. Rand Doble Engineering Company "Laboratory Testing of Natural Ester Dielectric Liquids" Chemist's Perspective, 4, 2005.

[34] A. Thabet, A. Z. El-Dein, N. M. Youssef, "Frequency Modulation Response for Effective Dielectric Response of New Nanocomposite Liquids", International Review on Modelling and Simulations (I.RE.MO.S), Vol.5, No. 3, pp $.1348-1355,2012$. 